\title{
Reduction in mydriatic drop size in premature infants
}

\author{
S Wheatcroft, A Sharma, J McAllister
}

\begin{abstract}
In a prospective study of 26 premature infants, $5 \mu$ microdrops were compared with standard $26 \mu \mathrm{l}$ eye drops of cyclopentolate $0.5 \%$ and phenylephrine $2 \cdot 5 \%$. There was no statistical difference in pupil dilatation. The $5 \mu l$ microdrops have potentially fewer adverse effects in premature infants.
\end{abstract}

(Brf Ophthalmol 1993; 77: 364-365)

Systemic toxicity from cyclopentolate and phenylephrine eye drops is well documented in adults and children. ${ }^{12}$ Screening all at risk infants for retinopathy of prematurity is now recommended. ${ }^{3}$ Cyclopentolate drops $0.5 \%$ and phenylephrine drops $2.5 \%$ are suggested for pupil dilatation in neonates but even these lower strengths have been shown to have systemic effects. $^{3-5}$ This paper presents the results of a prospective study on the effect on pupil dilatation when mydriatic drop size is reduced to $5 \mu \mathrm{l}$ from the standard $26 \mu l$.

\section{Methods}

Twenty six preterm infants referred for screening for retinopathy were included. One eye was dilated with a standard $26 \mu$ l drop from a Smith and Nephew minim of both cyclopentolate $0.5 \%$ and phenylephrine $2.5 \%$. The other eye was dilated with a $5 \mu \mathrm{l}$ drop of each drug delivered via a 30 gauge Ryecroft intraocular cannula attached to the minim. ${ }^{6}$ The two drugs were instilled 5 minutes apart. Some 40-60 minutes later the eyes were photographed with a macrolens giving a 1:1 image size on the transparency. The photographs were randomised and the pupil size was measured from the transparency.

\section{Results}

The mean postnatal age of the infants was $7 \cdot 4$ weeks (range 5 to 12 weeks), mean gestation 29.8 weeks (range 25 to 34 weeks), and mean birth weight 1238 grams (range $690 \mathrm{~g}$ to $2010 \mathrm{~g}$ ). There were 12 female and 14 male infants. The mean pupil diameter was $6.05 \mathrm{~mm}$ (range 4.5 to $7 \cdot 1 \mathrm{~mm}$ ) in the eyes dilated with standard sized drops and $6.1 \mathrm{~mm}$ (range 5.0 to $7.5 \mathrm{~mm}$ ) in those dilated with microdrops. A matched Student's $t$ test showed a $t$ value of $0 \cdot 426$. There was no statistical difference $(p>0 \cdot 1)$ in pupil dilatation between the two groups.

\section{Discussion}

The volume of an eye drop from a minim is $26 \mu l^{6}$ which is greatly in excess of the adult precorneal tear film volume of $7 \mu \mathrm{l} .^{7}$ Eighty per cent of standard drops may be lost in the first 15-30 seconds via the nasolacrimal duct, conjunctival blood vessels, or spillage onto the skin. Systemic absorption is directly into the circulation from the conjunctival and nasal mucosa without first pass metabolism in the liver. Therefore systemically absorbed eye drops are more like intravenous agents than oral ones.'

There was no statistically significant difference in pupil dilatation in this study between the smaller $5 \mu \mathrm{l}$ drop size and the conventional $26 \mu \mathrm{l}$ drop size. Equal pupil dilatation has been demonstrated with $8 \mu \mathrm{l}$ and $30 \mu \mathrm{l}$ drops of phenylephrine in neonates but the pupil size was only $4.86 \mathrm{~mm}$ and $4.57 \mathrm{~mm}$ respectively.$^{8}$ The pupil diameter was larger in this study which is compatible with the results of Carpel and Kalina who showed there was an additional effect in premature infants when cyclopentolate was added. ${ }^{9}$ In adults reduction in drop size of phenylephrine $10 \%$ and tropicamide $1 \%$ produces adequate mydriasis. ${ }^{6}$

Brown et al have shown that drop size can be reduced by designing a bottle with a narrower outlet. ${ }^{10}$ The systemic absorption is less with a smaller than a larger drop volume. ${ }^{8}$ Infants in particular may be more likely to absorb eye drops systemically as the tear volume is small and the drops are instilled supine so that spillage onto the skin may be less. " The risk of toxicity may also be increased because of low body mass and the immaturity of the cardiovascular and nervous systems. ${ }^{4}$

Cyclopentolate in adults and children may cause psychosis, behavioural disturbance, ataxia, agitation, fits, and gastrointestinal upset. ${ }^{12}$ Preterm twins developed gastrointestinal side effects from cyclopentolate $1 \%$, and abdominal distension and increased gastric aspirate was reported in 50 preterm infants examined for retinopathy of prematurity. ${ }^{512}$ There are many reports of cardiovascular adverse effects from phenylephrine. $^{12}$ Raised blood pressure has been observed in preterm infants after dilatation with $2.5 \%$ phenylephrine and this potentially increases the risk of intraventricular haemorrhage. ${ }^{413}$

The risk of adverse systemic effects from eye drops is well recognised and as more and more premature babies are being examined it would be better medical practice not to use over five times more medication than is required.

1 Palmer EA. How safe are ocular drugs in pediatrics? Ophthalmology 1986; 93: 1038-40.

2 Rengstorff RH, Doughty CB. Mydriatic and cycloplegic drugs: a review of ocular and systemic complications. Am F Optom Physiol Opt 1982; 59: 162-77.

3 Levene M, Garner A, Johnston S, Rennie J, Schulenberg E, Fielder A. Screening for retinopathy of prematurity. 1990 Working Party Report for the College of Ophthalmologists

4 Rosales T, Isenberg S, Leake R, Everett S. Systemic effects of mydriatics in low weight infants. $\mathcal{F}$ Pediatr Ophthalmo Strabismus 1981; 18: 42-4. 
5 Hermansen MC, Sullivan LS. Feeding intolerance following ophthalmologic examination. Am $\mathcal{F}$ Dis Child 1985; 139: 367-8.

6 Gray $\mathrm{RH}$. The influence of drop size on pupil dilatation. Eye 1991; 5: 615-9.

7 Shell JW. Pharmacokinetics of topically applied ophthalmic drugs. Surv Ophthalmol 1982; 26: 207-18.

8 Lynch MG, Brown RH, Goode SM, Schoenwald RD, Chien $D$. Reduction of phenylephrine drop size in infants achieves equal dilation with decreased systemic absorption. Arch Ophthalmol 1987; 105: 1364-5.

9 Carpel EF, Kalina RE. Pupillary responses to mydriatic agents in premature infants. Am $\mathcal{f}$ Ophthalmol 1973; 75: 988-91.
10 Brown RH, Hotchkiss ML, Davis EB. Creating smaller eyedrops by reducing eyedropper tip dimensions. Am $\mathcal{F}$ Ophthalmol 1985; 99: 460-4.

11 Lynch MG, Brown RH. Systemic side effects of glaucoma therapy. Clinical modules for ophthalmologists. Focal points 1990. American Academy of Ophthalmology. Vol VIII, module 4: 1-10.

12 Bauer CR, Trottier MCT, Stern L. Systemic cyclopentolate toxicity in the newborn infant. $\mathcal{F}$ Pediatr 1973; 82:

13 Lees BJ, Cabal LA. Increased blood pressure following pupillary dilation with $2.5 \%$ phenylephrine hydrochloride in preterm infants. Pediatrics 1981; 68: 231-4.

\section{History of ophthalmology}

\section{Ophthalmological quacks and mountebanks}

Eighteenth century medicine was bedevilled by what the historian Harvey Graham calls a 'monstrous army of quacks and mountebanks.' The three most florid examples, a tinker, a tailor, and a poseur, were all in the field of ophthalmology.

Dr Roger Grant (former tinker), rose to the rank of royal oculist owing to his skill in restoring sight to dozens of blind peasants. History records that his only real skill was in bribing local clergymen - with suitable donations to church funds - to sign his (false) testimonials. Unsurprisingly, Queen Anne's eyesight always remained weak.

The tailor, William Read, was actually knighted for 'curing great numbers of soldiers of blindness,' most probably on similar therapeutic principles as Grant, whom he joined as second oculist to the Queen. Apparently the famous Cheselden made frequent disparaging remarks about both these gentlemen, as did the general public, who frequently sang the following verse in the coffee houses:

Her Majesty, sure, was in a surprise,

Or else was very short-sighted,

When a tinker was sworn to look after her eyes

And the mountebank Read was knighted.

The third 'quack ophthalmologist,' John Taylor, was the son of a Norwich surgeon, and even studied under Cheselden for a while. Taylor called himself 'the chevalier' (so much more catchy than doctor), dressed in black, and drove round in a magnificently ostentatious "coach and four.' Dr Johnson thought him a prime example of 'how far impudence could carry ignorance.'

Taylor deliberately cultivated an obscure mode of speech, so as to appear more intelligent than his patients (some might say the profession still does so). An example survives: 'of the eye, on the wonders, lecture will I.' He also claimed to have more royal patients than were actually living, and to have treated Hugh Walpole (who nearly choked in outrage on hearing this - rushing off to compose a series of stingingly sarcastic denials). Cheselden, his former tutor, must have been cringing at his exploits. His claim to have treated Handel, however, was correct. Fortunately for the musical world, he did him no damage. And to his credit, Taylor is reported to have performed the first operation to cure squint, successfully cutting the interior rectus muscle in 1738.

Current concerns over plagiarism in research almost pale into insignificance compared with Read's bribing of dozens of soldiers to swear to his colleagues that they were formerly blind.

Grant, Read, and Taylor were lucky to evade punishment for their 'quackery.' Dr John Lambe was imprisoned by the College of Physicians for the same crime and, worse, was battered to death by the public on his release. Quacks who had killed a patient by giving the wrong drug treatment were committed to the tower. This evokes sentiments of 'there but for the grace of God ....' except that overdoses of mercury and antimony was what they had in mind.

Other 'quacks' were placed in the pillory so that the public - even less polite than they are now - could throw mud and rotten eggs at them and generally abuse them.

Today, of course, all three would merely be struck off for malpractice, though Taylor, at least, would easily regain his fame and fortune in the sphere of public relations. Or possibly at Westminster.

FIONA ROMAN

Beier LM. Sufferers and healers. London: Routledge and Kegan, 1987: $20-5$

Copeman WSC. Doctors and disease in Tudor times. London: Dawsons of Pall Mall, 1960: 56-8, 98-9.

Graham H. The quacks and the brothers. In: Surgeons all. London: Rich and Cowan Ltd, 1939: 222-3.

Haggard HW. The doctor in history. New Haven, CT: Yale University Press, 1934: 261-2.
Un

Singer C, Underwood EA. A short history of medicine. Oxford: Oxford University Press, 1962: 648.
Oent 